\title{
NUMERICAL INVESTIGATION OF NATURAL CONVECTIVE HEAT TRANSFER ON
}

\section{FLAT NARROW PLATES}

\author{
SAVITRI VEMIREDDI ${ }^{1}$, K.HARISH KUMAR ${ }^{2}$, A.SHANTHI SWAROOPINI ${ }^{3} \&$ DADI PRAKASH ${ }^{4}$ \\ ${ }^{1,2,3}$ Department of Mechanical Engineering, Vignan's Institute of Information Technology, Vizag, India. \\ ${ }^{4}$ B.Tech IV Year, Department of Mechanical Engineering, Vignan's Institute of Information Technology, India
}

\begin{abstract}
The Natural convective heat transfer rate in isothermal narrow plates are experimentally and numerically studied. In a 3dimensional model if one dimension compared, less than other dimensions then heat transfer rate is read high in value and this can be calculated by experimentation two-dimensional flow analysis. The fluid properties are assumed constant, the change of density with the temperature generates buoyancy forces. Experimental natural convection heat transfer analysis is conducted on narrow plates placing in various positions to know its effect on convection and their particular co-efficient of heat transfer are known. Dimension less numbers such as Grashof's Number and Prandtl Number are vital in calculations. This experimentation helped in the study of convection of three different substances and their importance to be used in particular applications. The experimentation briefed the convection rate and concluded that Copper has high convection rate and Aluminium shows high convection rate when the dimensional thickness of Aluminium is half that of copper. Experiments showed that Aluminium can be cheaper substitute of copper in various applications. Analysis is done to know the heat flow pattern inside the solid.

KEYWORDS: Nusselt Number, Prandtl Number, Grashof Number, Ambient Temperature\&Dynamic Viscosity
\end{abstract}

Received: Jun 08, 2020; Accepted: Jun 28, 2020; Published: Aug 21, 2020; Paper Id.: IJMPERDJUN2020847

\section{NOMENCLATURE}

h:convective heat transfer coefficient $\mathrm{W} / \mathrm{m}^{2} \mathrm{~K}$

Q:Convection (W)

q:heat transfer rate

Nu: Nusselt Number

Pr:Prandtl Number

Gr: Grashof Number

T:Temperature

$\mathbf{T}_{\mathbf{s}}$ :Average Surface Temperature

$\mathbf{T}_{\mathrm{a}: \text { Ambient Temperature }}$

$\boldsymbol{\mu}$ :Dynamic Viscosity

v:Kinematic Viscosity 
k:Thermal Conductivity

g:Acceleration due to gravity

$\boldsymbol{\beta}:$ Coefficient of Volumetric expansion of fluid

$\mathbf{L}:$ Characteristic length

$\Delta \mathrm{T}$ : Change in Temperature

\title{
INTRODUCTION
}

Convection heat transfer mode embrace energy transfer due to specific molecular motion (diffusion) where energy is transferred either by bulk, or macroscopic, motion of the fluid. This motion is a fact that, at any instant, high numbers of molecules are moving collectively.

\section{Symbols:}

\author{
Nu: Nusselt Number \\ Gr:Grashof Number \\ Pr:Prandtl Number \\ Q:Convective Heat Transfer
}

h:Convective Heat Transfer Coefficient

The Preview was Numerical studies were conducted on natural-convection heat transfer above and below an isothermal thin plate in an infinite space and conservation equations for laminar flows were solved and results are shown. Results for upward- and downward-facing isothermal horizontal plates (single-sided heat transfer) were shown in comparison. Nusselt numbers on the upward-facing surface are larger than those on the downward-facing surface.[1] Influence of unsteady flow structures in natural convection had been studied on the heat transfer from a vertical flat plate to air, the deviations shows a there is a dependence on the mean Grashof number, as well as other influencing factors.[2] Some researches on free convection between two heated parallel plates had been carried out without using any boundarylayer approximation, flow rate with consideration of the pressure dropis proposed.[3]Fluid flow characteristics in horizontal and vertical narrow enclosures with heated finned plate have been experimented at a wide range of Rayleigh number (Ra), Optimization of fin-array geometry had been shown through their work.[4]Sometimes relations between Nusselt and Grashof numbers show same tendency and the experimental results give slightly lower Nusselt numbers comparatively[5].Natural convection flow and heat transfer from a horizontal plates. These plates are made of two different metals, copper and steel. Calculations for semi-infinite plate are carried out, transverse profiles of the surface temperature and heat flux are predicted and to visualize the structure of the flow. Three-dimensional calculations are also used at a qualitative level to observe the changes in the flow structure due to the finite length of the plate [6]. Natural convective heat transfer rate from a vertical isothermal plate has been numerically studied. The solution has the Rayleigh number, the dimensionless plate width and the Prandtl number as parameters [7]. Research on The steady mixed convection boundary layer flow past a vertical flat plate embedded in a porous medium filled with nanofluids. The effects of these parameters on the velocity distribution are presented graphically [8]. Heat-transfer efficiency enhancement and the hydraulic dissipated power increment is also discussed [9]. Convective heat transfer coefficient and pressure drop correlations reported in 
literature are also presented [10].

\section{EXPERIMENTATION}

To determine the natural convection heat transfer coefficient for the Narrow Plates which are exposed to the air and losing heat by natural convection.

The purpose of this experiment is to study experimentally the natural convection of Narrow plates at various positions of placements.

The Test Session is placement of Narrow Plates Over A heater in Horizontal and vertical Positions and voltage is applied the supply is regulated by a wattmeter. Thermocouples are placed at different positions for readings. The present experimental setup is designed and fabricated to study the natural convection phenomenon from narrow plates in terms of the variation of the local heat transfer coefficient and its comparison with the value which is obtained by using an appropriate correlation.

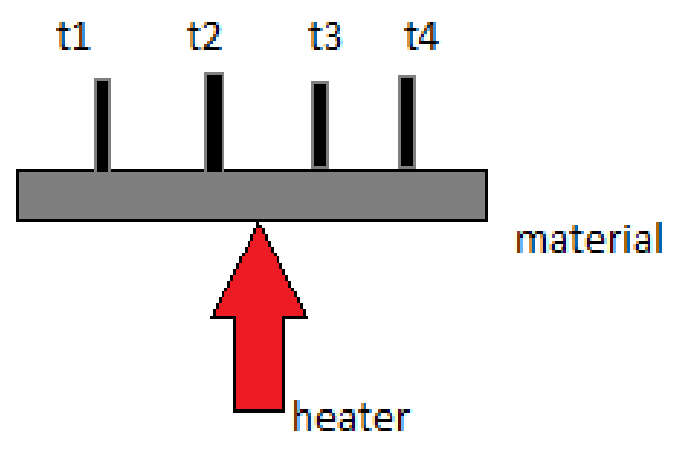

Figure 1: Horizontal PositioningExperimentation

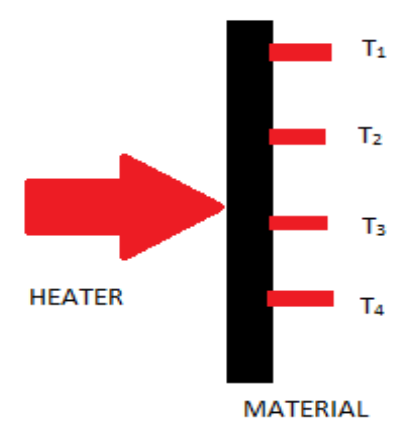

Figure 2: Vertical Positioning Experimentation

Fig 1 shows the pictorial representation of the experimental setup where the testing specimen is placed horizontally and heater is placed downwards as shown in the figure.

Fig 2 shows the pictorial representation of the experimental setup where the testing specimen is placed vertically and heater is placed at the back face of the specimen as shown in the figure. The whole apparatus is fixed to the position. 


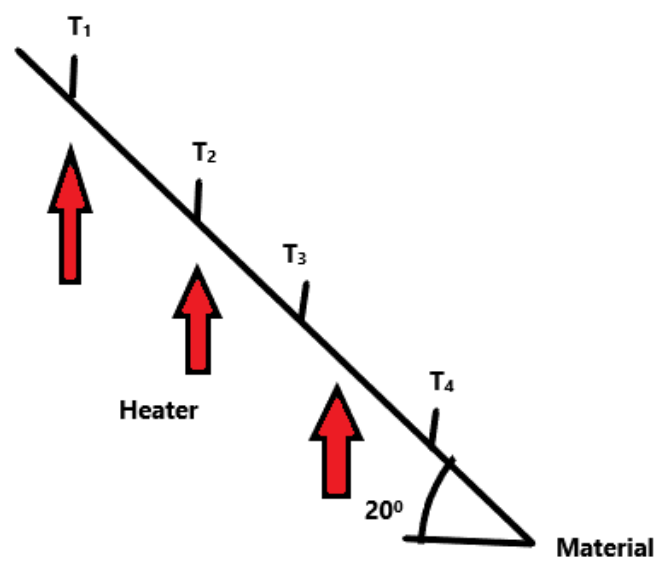

Figure 3: Inclined Positioning Experiment

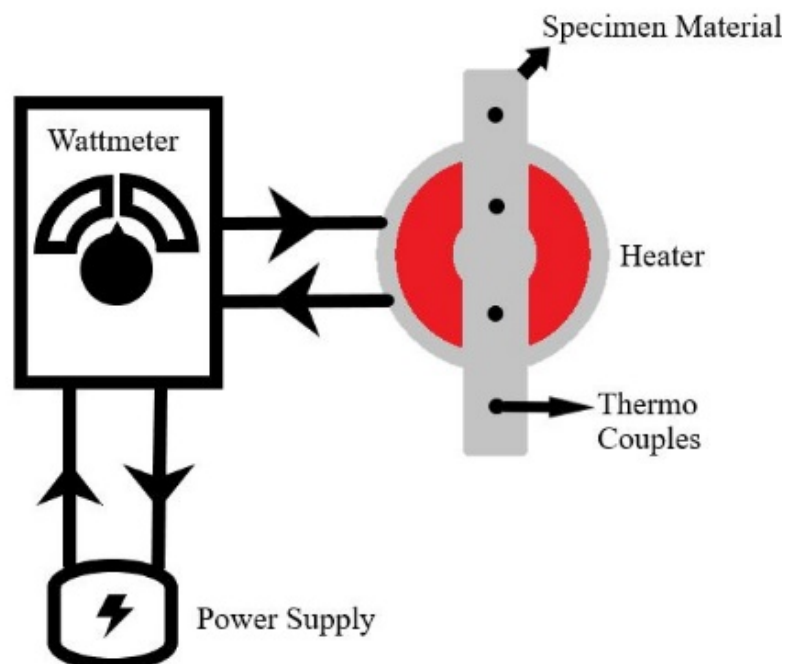

Figure 4: Block Diagram of Experiment

Fig 3 shows the pictorial representation of the experimental setup where the testing specimen is placed Inclined at an angle of $20^{\circ}$ and heater is placed at the back face of the specimen as shown in the figure. The whole apparatus is fixed to the position.

Fig 4 shows the experimental setup power supply is given to the heater placing a watt meter between that regulates the current flow and above the heater metal specimens are placed with thermocouples inserted in them.

In Convective heat Transfer Experimental Setup, Heater is of 700W and 230V, K-Type Thermocouples (4) are used. Material used $=$ copper, aluminium, stainless steel with Dimensions ofcopper $(500 * 40 * 6) \mathrm{mm}^{3}$, aluminium $(500 * 40 * 3) \mathrm{mm}^{3}$, stainless steel $(500 * 40 * 4) \mathrm{mm}^{3}$.Iron Stand for placing the setup, Bolts and Nuts to fix the plates and Heater.

The experimental procedure is that Switchon the supply and adjustthe dimmer stat to obtain the required heat input (say 200W). Monitor the temperature T1 to T4 every five minutes till steady state is reached. Wait till the steady state is reached. This is confirmed from temperature readings (T1 to T4). Measure the surface temperature at various points (T1 to T4).Note the ambient temperature, To.Repeat the experiment for different heat inputs by varying dimmer stat position. 
Table 1: Observation of the Specimen Dimensions Used for the Experimentation

\begin{tabular}{|l|c|c|c|}
\hline \multicolumn{1}{|c|}{ Material } & $\begin{array}{c}\text { Length } \\
\text { In(mm) }\end{array}$ & $\begin{array}{c}\text { Breadth } \\
\text { In(mm) }\end{array}$ & $\begin{array}{c}\text { Thickness } \\
\text { In(mm) }\end{array}$ \\
\hline Copper(Cu) & 500 & 40 & 6 \\
\hline Aluminium(Al) & 500 & 40 & 3 \\
\hline Stainless Steel(SS) & 500 & 40 & 4 \\
\hline
\end{tabular}

The above table gives us the values of dimensions of the material specimens used.

\section{THEORY/BACKGROUND}

When any hot body is kept in a still atmosphere, heat is convicted and transferred to the surrounding fluid by natural convection. The process is continuous and heat transfer takes place due to the relative motion of hot and cold particles.

The heat transfer coefficient is given by:

$$
h=\frac{q}{A_{s}\left(T_{s}-T_{a}\right)}
$$

Here,

$\mathrm{h}=$ Average surface heat transfer coefficient.

$q=$ Heat transfer rate.

As $=$ Area of heat transferring surface

Ts $=$ Average surface temperature $\left({ }^{\circ} \mathrm{C}\right)$,

Where,

$$
T_{s}=\frac{T_{1}+T_{2}+T_{3}+T_{4}}{4}
$$

$\mathrm{Ta}=$ Ambient temperature in the $\operatorname{duct}\left({ }^{\circ} \mathrm{C}\right)=\mathrm{T} 5$

The dependence of ' $h$ ' on all the above-mentioned parameters is generally expressed in terms of non-dimensional groups, as follows:

$$
\frac{\mathrm{h} L}{k}=A\left[\left\{\frac{g L^{3} \beta \Delta T}{v^{2}}\right\}\left\{\frac{\mu C_{p}}{k}\right\}\right]^{n}
$$

$$
\begin{aligned}
& \text { Here, } \\
& \frac{h L}{k} \text { is called the Nusselt Number } \frac{g L^{3} \beta \Delta T}{v^{2}} \text { is called the Grashoff Number (Gr) and, }
\end{aligned}
$$

\section{RESULTS AND DISCUSSIONS}


Horizontal Postion of Materials

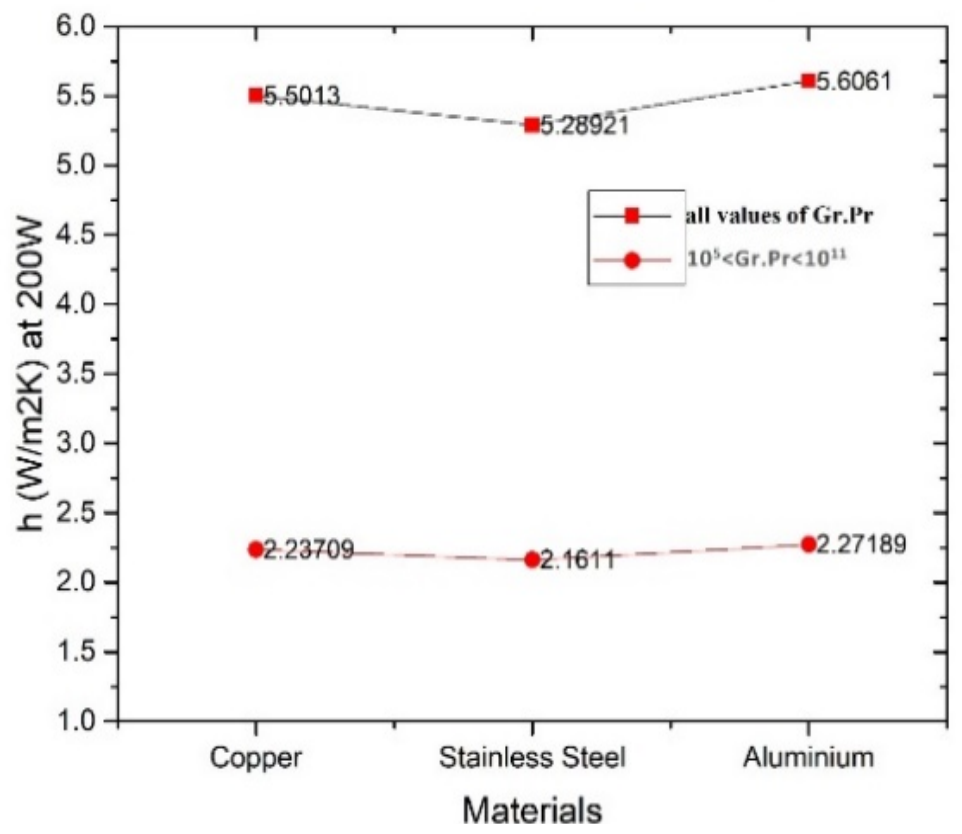

Figure 5: Convective Heat Transfer Coefficient of Materials When Placed in Horizontal Position

Fig. 5 is a graph plotted between materials to their corresponding convective heat transfer coefficient $\mathrm{h}$ value experimented in Horizontal position. Here the Values exhibited by Aluminium are very high, h is $5.6061 \mathrm{~W} / \mathrm{m}^{2} \mathrm{k}$ for all values of Gr.Prthis could be due to the less thickness of aluminium. Copper nearly exhibited same values,h is 5.5013 $\mathrm{W} / \mathrm{m}^{2} \mathrm{k}$ for all values of Gr.Prbut the thickness of copper is double to that of aluminium and Stainless Steel does not show any better results as expected in thickness reduce. For $10^{5}<\mathrm{Gr} . \operatorname{Pr}<10^{11} \mathrm{~h}$ is $2.27189 \mathrm{~W} / \mathrm{m}^{2} \mathrm{k}$ for aluminium whereas 2.20709 $\mathrm{W} / \mathrm{m}^{2} \mathrm{k}$ for copper.

The Materials from left to right has decrease in thickness, SS had not shown any effective results but there is increase in convection between copper and aluminium as the thickness decreases.

Fig 6 is a graph plotted between materials to their convective heat transfer coefficient $\mathrm{h}$ value experimented in vertical position. Here for all values of Gr.Pr values exhibited by Aluminium are very high, his $5.9355 \mathrm{~W} / \mathrm{m}^{2} \mathrm{~K}$ this could be due to the less thickness of aluminium. Copper nearly exhibited same values, his $5.7077 \mathrm{~W} / \mathrm{m}^{2} \mathrm{~K}$ but the thickness of copper is double to that of aluminium and Stainless Steel does not show any better results. For $10^{5}<\mathrm{Gr}$. $\operatorname{Pr}<10^{11} \mathrm{~h}$ is 2.3919 for aluminium and 2.3163 for copper.

The Materials from left to right has decrease in thickness, SS had not shown any effective results but there is increase in convection between copper and aluminium as the thickness decreases. 
Vertical Positions of materials

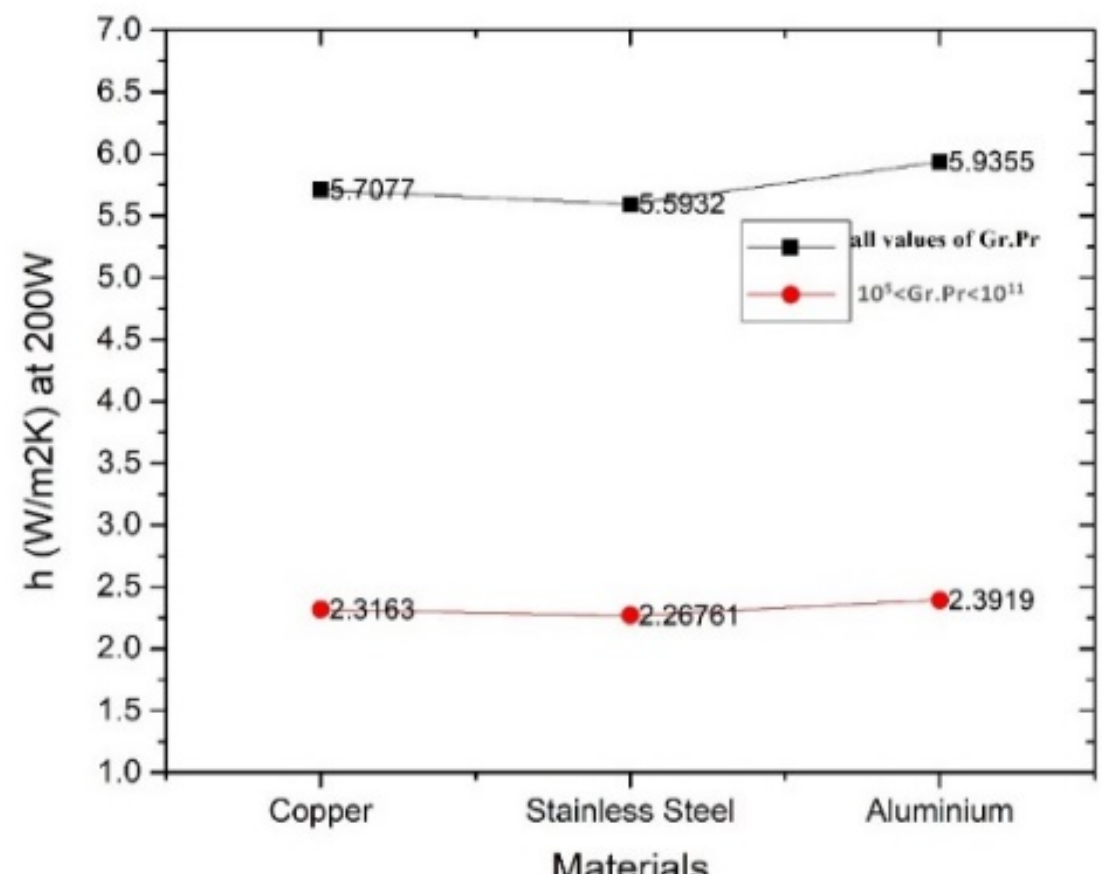

Figure6: Convective Heat Transfer Coefficient of Materials When Placed in Vertical Position

Fig 7 is a graph plotted between materials to their convective heat transfer coefficient $h$ value experimented in inclined $\left(20^{\circ}\right)$ position. Here for all values of Gr.Pr the values exhibited by Aluminium are very high, $\mathrm{h}$ is 5.566184 $\mathrm{W} / \mathrm{m}^{2} \mathrm{~K}$ this could be due to the less thickness of aluminium. Copper nearly exhibited same values, $\mathrm{h}$ is $5.4985 \mathrm{~W} / \mathrm{m}^{2} \mathrm{~K}$ but the thickness of copper is double to that of aluminium and Stainless Steel does not show any better results. For $10^{5}<\mathrm{Gr} . \operatorname{Pr}<10^{11} \mathrm{~h}$ is $2.2856 \mathrm{~W} / \mathrm{m}^{2} \mathrm{k}$ for aluminium and $2.2256 \mathrm{~W} / \mathrm{m}^{2} \mathrm{k}$ for copper.

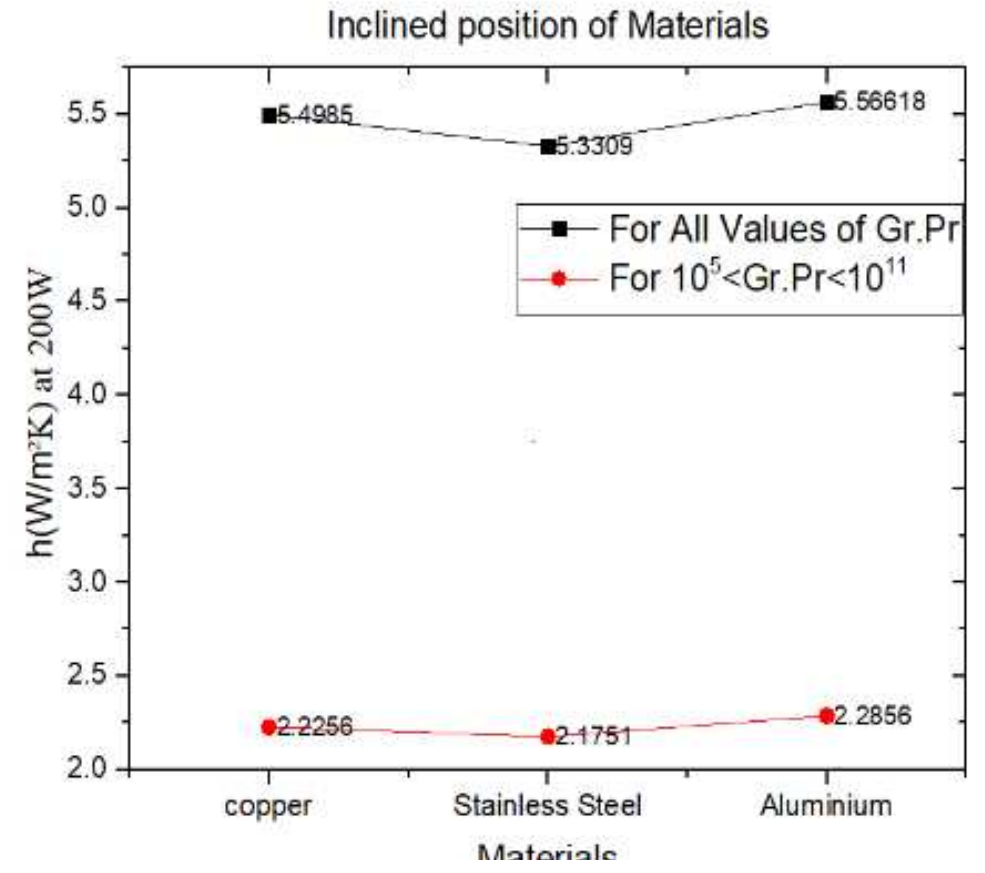

Figure 7: Convective Heat Transfer Coefficient of Materials When Placed in Inclined Position 
The Materials from left to right has decrease in thickness, SS had not shown any effective results but there is increase in convection between copper and aluminium as the thickness decreases.

In above graphs Convective heat transfer Coefficient " $h$ " $\left(\mathrm{W} / \mathrm{m}^{2} \mathrm{~K}\right)$ is shown for various metals in similar experiment from varying positions the $\mathrm{Y}$ axis represents ' $h$ ' $\left(\mathrm{W} / \mathrm{m}^{2} \mathrm{~K}\right)$ and $\mathrm{X}$ axis is given for materials. The ' $h$ ' $\left(\mathrm{W} / \mathrm{m}^{2} \mathrm{~K}\right)$ obtained here are for all values of Gr.Pr and $10^{6}<\mathrm{Gr}$. $\operatorname{Pr}<10^{11}$. The above graphs give the information about the Convective heat transfer coefficient of the materials in their respective positions placed. The Final values obtained, in which Vertical positioning values are high compared to other two as the gravity played a role in natural convection, since natural convection is all about buoyancy forces.Aluminium had shown Greater values as the thickness of Aluminium is half to that of copper thickness. Copper showed relatively similar values the values in graphs. Aluminium is less conductive when compared to copper naturally but when the thickness of aluminium is reduced it showed greater convection rate. If copper thickness is further reduced it could go to greater extents.

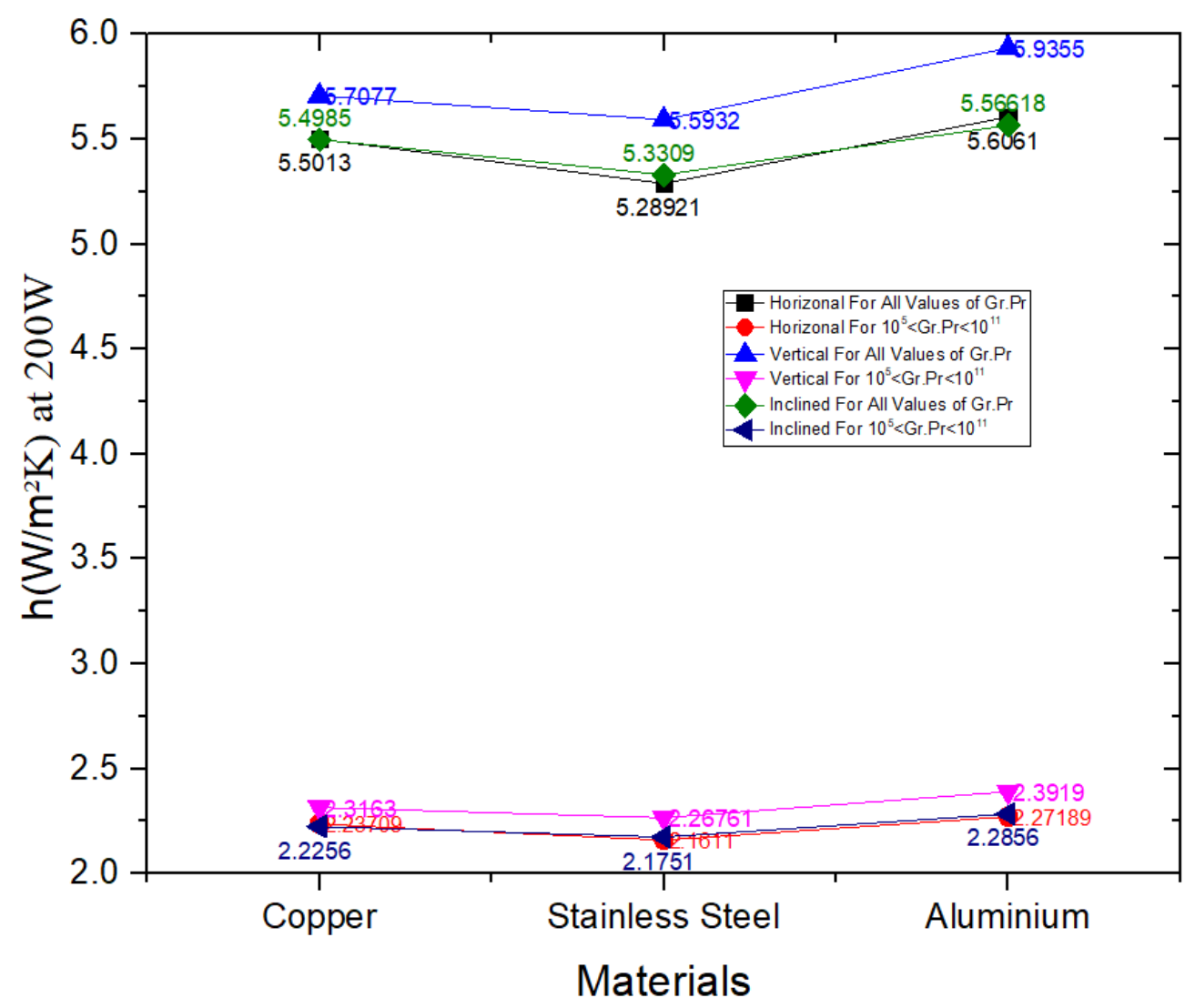

Figure8: Stack View of Convective Heat Transfer Rate (Vs.) Materials

Fig. 8 is a stack graph in which all the $\mathrm{h}$ vales are plotted in a single graph for differentiation of the three position outputs. The $\mathrm{h}$ values for all values of Gr.Pr are greater compared to the $\mathrm{h}$ values for $10^{5}<\mathrm{Gr}$. $\operatorname{Pr}<10^{11}$ due to the variation of theoretical formulae from heat transfer. 


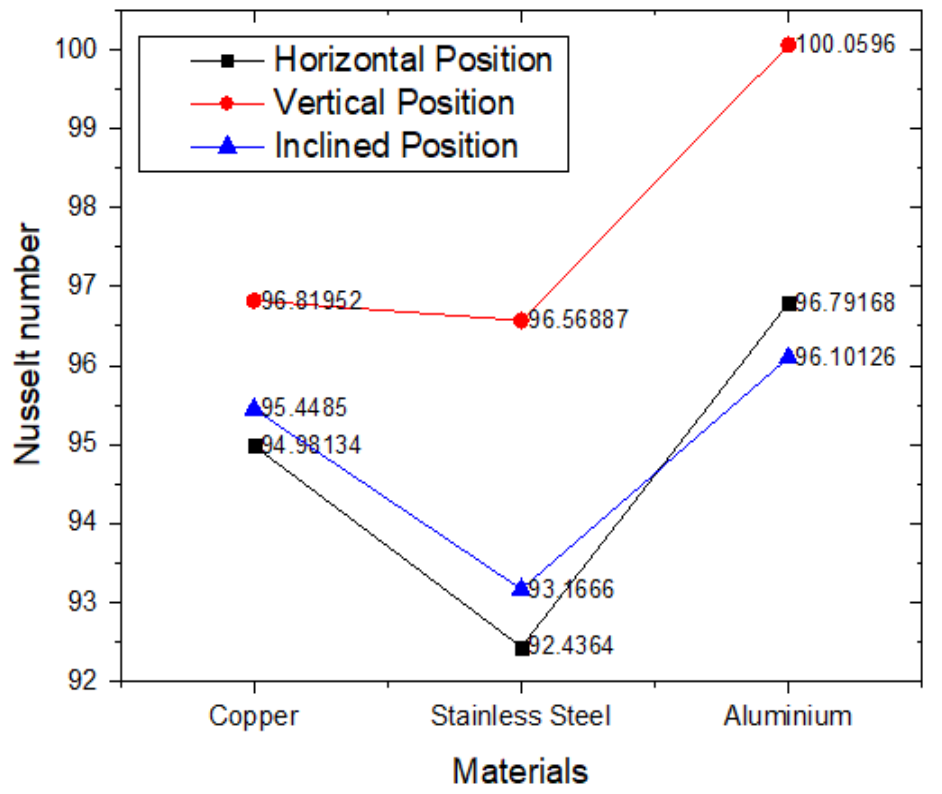

Figure 9: Various Nusselt Numbers Calculated by the Materials

Fig. 9 above explains the Nusselt numbers of the experiment whereas the vertical position had exhibited high values of Nusselt number aluminum had shown high values in Nusselt number resulting in high convection heat transfer rate.Similarly Nusselt numbers are also calculated and here is the graph of Nusselt number respective to materials. The Yaxis represents Nusselt Number and $\mathrm{X}$ axis is for materials.

The Highest Nusselt Numbers shown are 100.0596 at vertical position by aluminium, 96.79168 at horizontal position and 96.10126 at inclined position.

\section{Convection Heat Transfer Values}

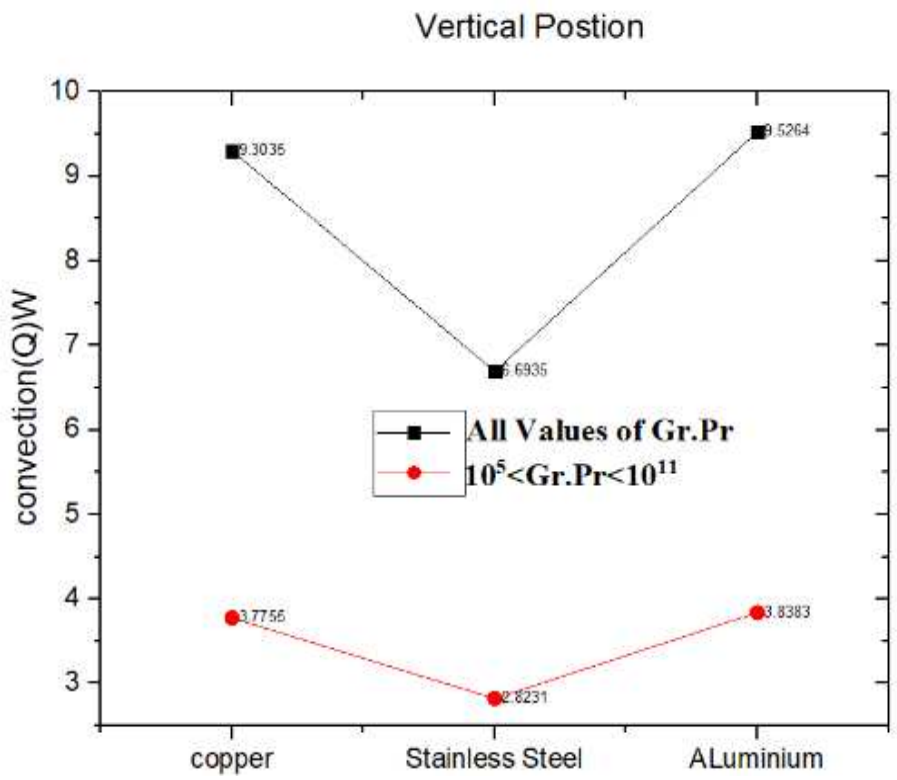

Figure 10: Convection Values Shown by Materials in Vertical Position

Fig 10 is graph plotted between materials and convection $(\mathrm{Q}) \mathrm{w}$ in vertical position, shows that aluminum showed greater convection, for All Values of Gr.Pr; Q is $9.5264 \mathrm{~W}$ and for $105<\mathrm{Gr} . \operatorname{Pr}<10^{11}$; Q is $3.8383 \mathrm{~W}$ and copper showed 
nearly similar values, for All Values of Gr.Pr; Q is $9.3035 \mathrm{~W}$ and for $10^{5}<\mathrm{Gr} . \operatorname{Pr}<10^{11}$; Q is $3.7755 \mathrm{~W}$.

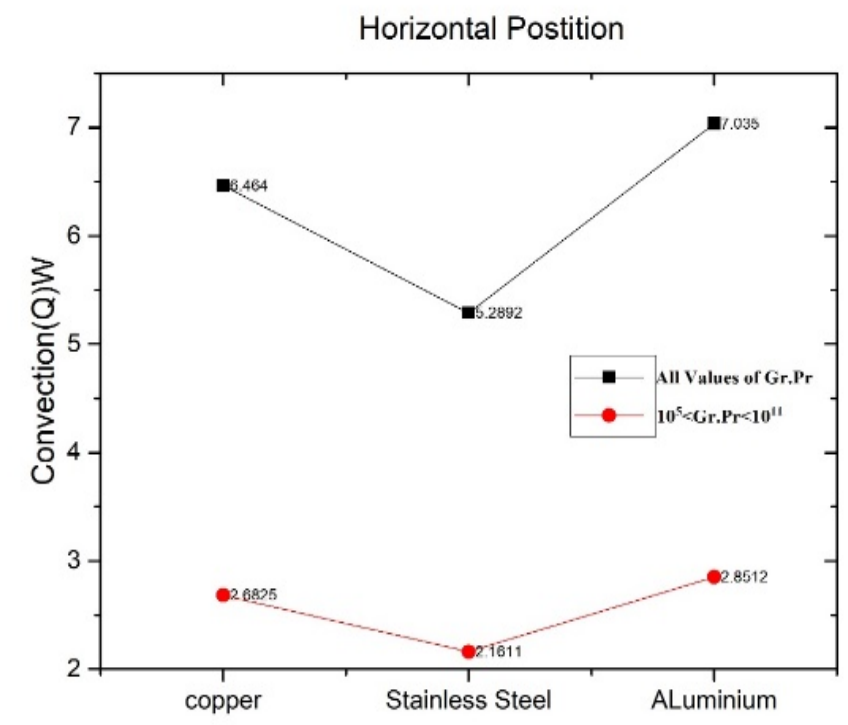

Figure 11: Convection Values Shown by Materials in Horizontal Position.

Fig. 11 is graph plotted between materials and convection (Q) w in Horizontal position, shows that aluminum showed greater convection, for All Values of Gr.Pr; Q is $7.035 \mathrm{~W}$ and for $105<\mathrm{Gr}$. $\operatorname{Pr}<10^{11}$; Q is 2.8512 Wand copper showed second high values, for All Values of Gr.Pr; Q is $6.464 \mathrm{~W}$ and for $105<\mathrm{Gr} . \operatorname{Pr}<10^{11}$; Q is $2.6825 \mathrm{~W}$.

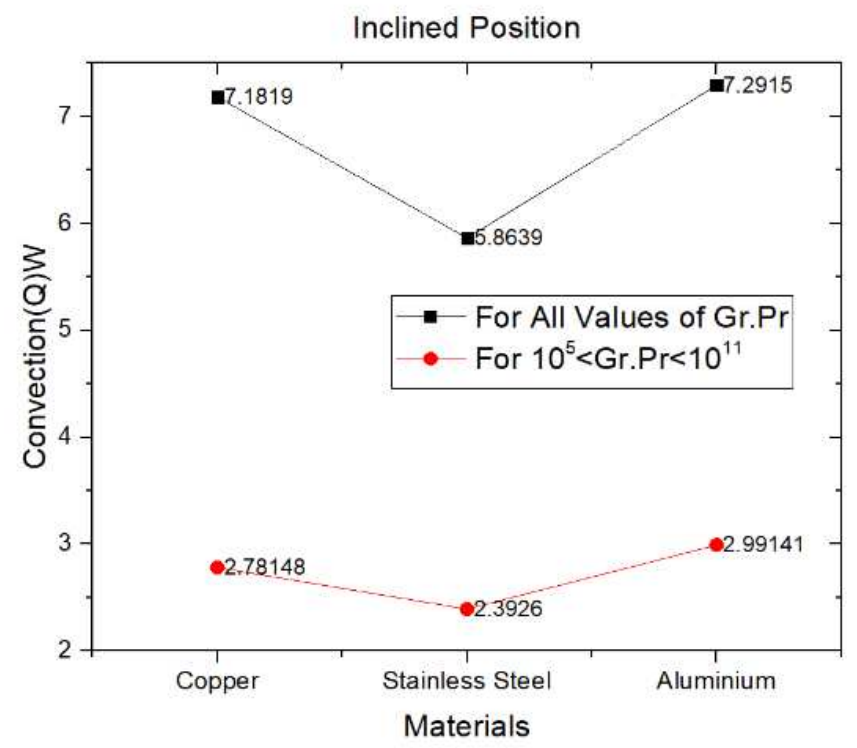

Figure 12: Convection Values Shown by Materials in Inclined Position.

Fig. 12 is graph plotted between materials and convection $(\mathrm{Q}) \mathrm{w}$ in Inclined $\left(20^{\circ}\right)$ position, shows that aluminum showed greater convection, for All Values of Gr.Pr; Q is $7.2915 \mathrm{~W}$ and for $105<\mathrm{Gr} . \operatorname{Pr}<10^{11}$; Q is $2.99141 \mathrm{~W}$ and copper showed second high values, for All Values of Gr.Pr; $\mathrm{Q}$ is $7.1819 \mathrm{~W}$ and for $105<\mathrm{Gr}$. $\operatorname{Pr}<10^{11}$; Q is $2.78148 \mathrm{~W}$ which are nearly similar to aluminum.

The above three graphs are the Convection $(\mathrm{Q})$ graphs for the three experiments of the materials. The Y-axis represents the Convection $(\mathrm{Q})$ and $\mathrm{X}$ axis is for materials. The Convection shown by Aluminium is really high due to 
thickness being less but copper shown similar convection though being double the thickness of Aluminium.The graphs shown that position of the materials effect the convection rate and less thickness materials show greater convection. Copper can show a greater extension of convection at less thickness.Aluminum can be the best substitute for copper in convective applications in terms of capital. Efficiency is almost similar.

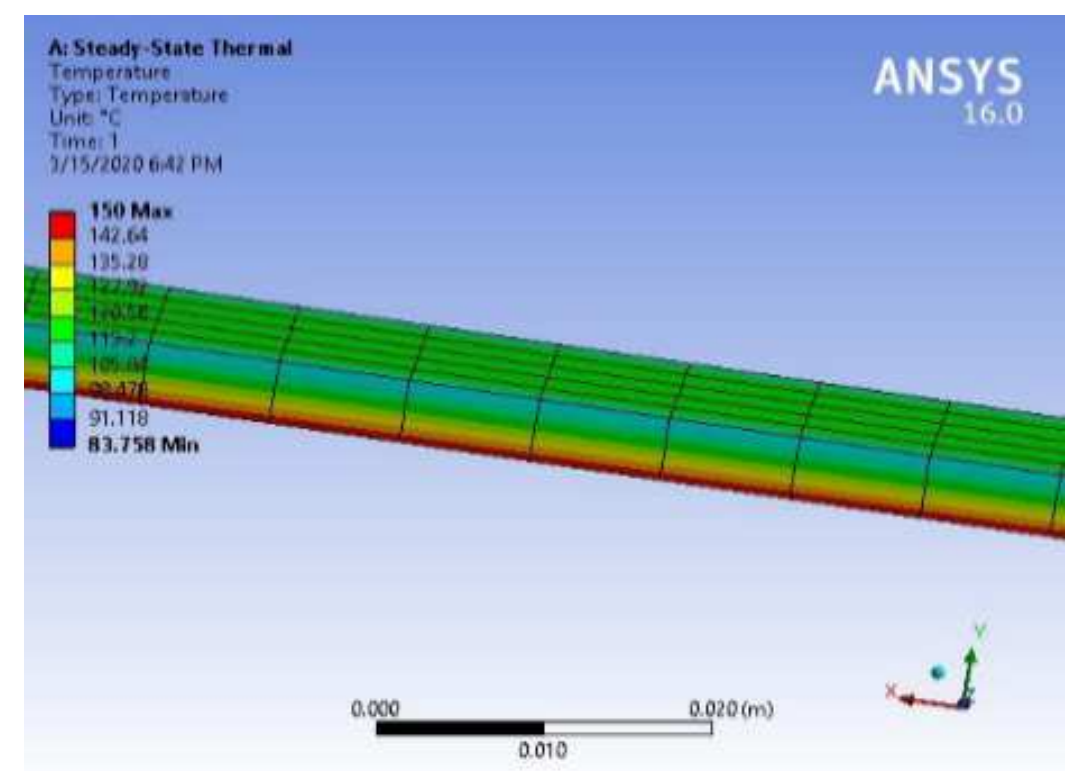

Figure 13: Temperature Variation in Copper

Fig.13 is a Simulation Image of internal Heat transfer of Copper plate as shown above done in ANSYS 16.0 the values exhibited as displayed to the left of the image are the temperature variation values along the thickness of the Copper plate.

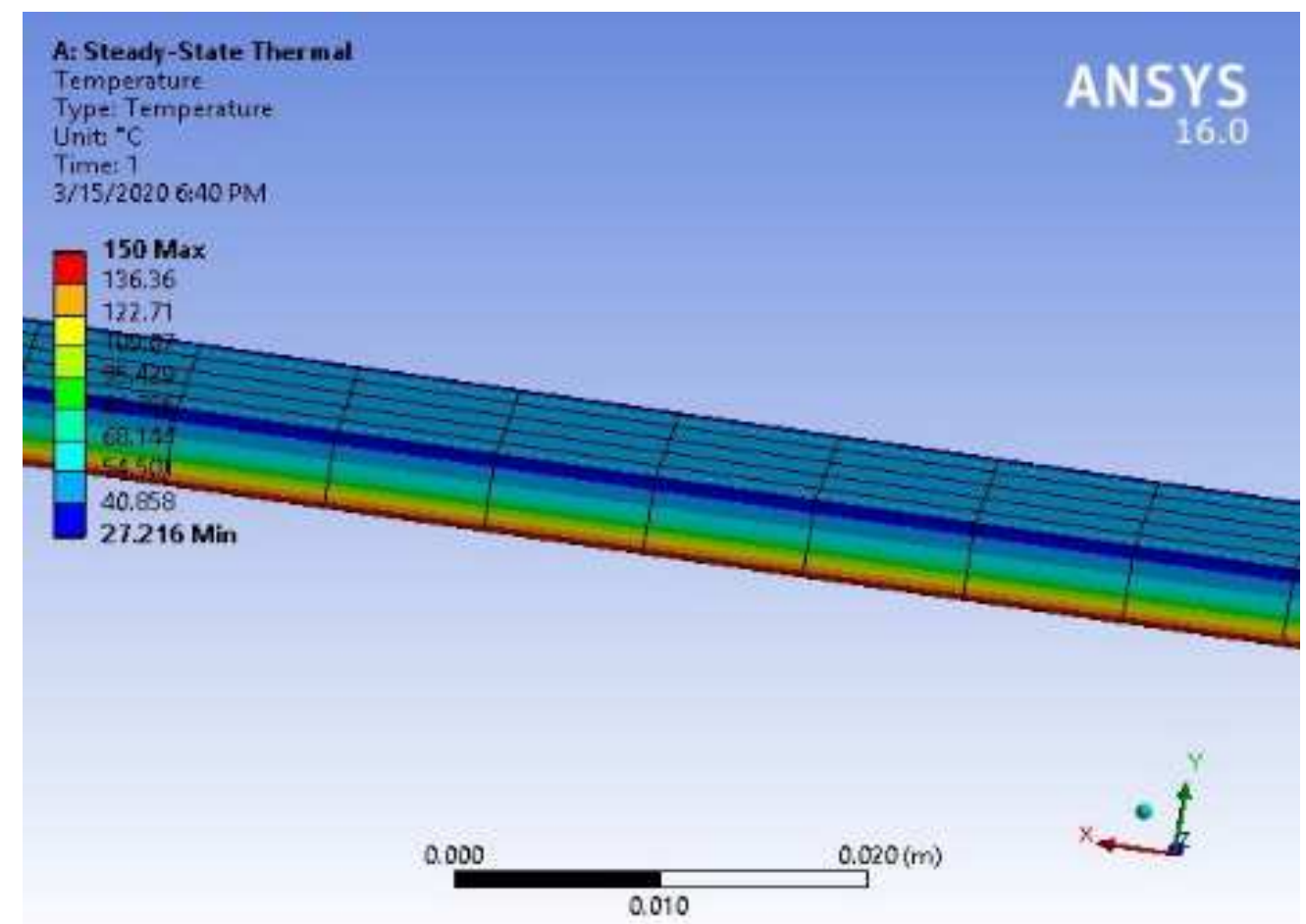

Figure 14: Temperature Variation in Stainless Steel 
Fig.14 is a Simulation Image of internal Heat transfer of Stainless Steel plate as shown above done in ANSYS 16.0 the values exhibited as displayed to the left of the image are the temperature variation values along the thickness of the Stainless Steel plate.

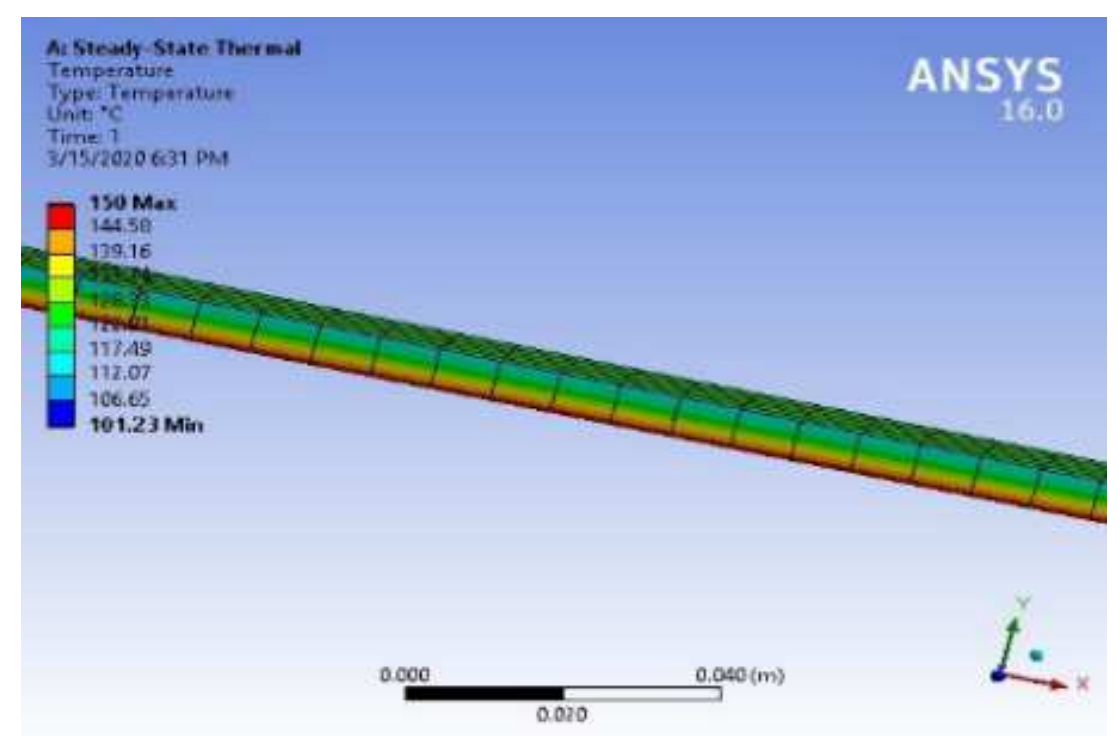

Figure 15:Temperature Variation in Aluminium.

Fig.15 is a Simulation Image of internal Heat transfer of Aluminium plate as shown above done in ANSYS 16.0 the values exhibited as displayed to the left of the image are the temperature variation values along the thickness of the Aluminium plate.

The above are the Steady State Thermal Images showing the heat transfer inside the body and from the images it is clear that as the aluminium thickness is low it showed less internal heat transfer. All the materials are not of equal Thickness. Aluminum specimen is $3 \mathrm{~mm}$ copper $6 \mathrm{~mm}$ and SS is $4 \mathrm{~mm}$ thick. The Temperature $\left({ }^{0} \mathrm{c}\right)$ variation is shown in graphs in which $\mathrm{Y}$ axis represents the temperature $\left({ }^{0} \mathrm{c}\right)$ and $\mathrm{x}$ axis is Position along the Thickness.

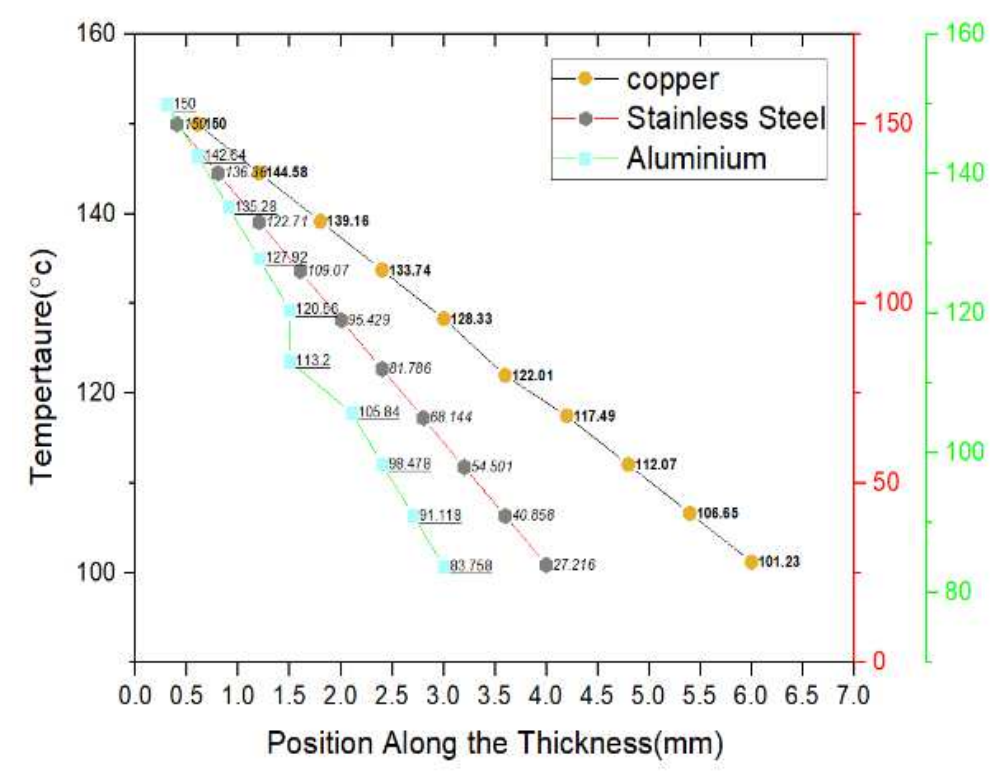

Figure16: Temperature Variation along the thickness of materials. 
Fig. 16 is plotted between temperature varied along the thickness of the material and in the above graph yellow dotted line indicates copper along $6 \mathrm{~mm}$ thickness and silver dotted line is for stainless steel and blue dotted line represents aluminium.

\section{CONCLUSIONS}

From the results it is concluded that the specimen Aluminium has shown its Vulnerability in convection but whereas Copper is to be treated as metal that exhibits high convection rate as considering the dimensions of two metals.Considering stainless Steel does not show much effect comparative to other two materials. The experimental values obtained are a way less than the theoretical values and it is due to the losses.Considerably aluminum is the best material to be used in natural convection as the factors such as price and effectiveness comes into Consideration. When the factor is only convection rate copper stands at the best place possible. Effect of thickness of a material had shown variation in convection and nearly less thickness material resulted high convection irrespective to material properties. Considering the temperature variation in ANSYS showed that the results had shown changes in varying thickness. This study helped that aluminium could be a proper substitute for Copper in material and capital in applications can be reduced.

\section{REFERENCES}

1. Wei, J. J., Yu, B., \& Kawaguchi, Y. (2003). Simultaneous natural-convection heat transfer above and below an isothermal horizontal thin plate. Numerical Heat Transfer: Part A: Applications, 44(1), 39-58.

2. Schaub, M., Kriegel, M., \& Brandt, S. (2019). Experimental investigation of heat transfer by unsteady natural convection at a vertical flat plate. International Journal of Heat and Mass Transfer, 136, 1186-1198.

3. Falah Ali Jassim, “Modeling of Transient Temperature Change in Finned Tube Heat Exchanger “, BEST: International Journal of Management, Information Technology and Engineering (BEST: IJMITE), Vol. 3, Issue 9, pp. $31-36$

4. Nakamura, H., Asako, Y., \&Naitou, T. (1982). Heat transfer by free convection between two parallel flat plates. Numerical Heat Transfer, Part A Applications, 5(1), 95-106.

5. Nada, S. A. (2007). Natural convection heat transfer in horizontal and vertical closed narrow enclosures with heated rectangular finned base plate. International journal of heat and mass transfer, 50(3-4), 667-679.

6. Amir Qashqaei \& Ramin Ghasemi Asl, "Numerical Modeling and Simulation of Copper Oxide nanofluids Used in Compact Heat Exchangers “, International Journal of Mechanical Engineering (IJME), Vol. 4, Issue 2, pp. 1-8

7. Miyamoto, M., Katoh, Y., Kurima, J., Kurihara, S., \& Yamashita, K. (1985). Free convection heat transfer from vertical and horizontal short plates. International journal of heat and mass transfer, 28(9), 1733-1745.

8. Martorell, I., Herrero, J., \& Grau, F. X. (2003). Natural convection from narrow horizontal plates at moderate Rayleigh numbers. International Journal of heat and mass transfer, 46(13), 2389-2402.

9. Oosthuizen, P., \& Paul, J. (2006). Natural convective heat transfer from a narrow isothermal vertical flat plate. In 9th AIAA/ASME Joint Thermophysics and Heat Transfer Conference (p. 3397).

10. Ahmad, S., \& Pop, I. (2010). Mixed convection boundary layer flow from a vertical flat plate embedded in a porous medium filled with nanofluids. International Communications in Heat and Mass Transfer, 37(8), 987-991.

11. Ho, C. D., Yeh, H. M., \& Wang, R. C. (2005). Heat-transfer enhancement in double-pass flat-plate solar air heaters with recycle. Energy, 30(15), 2796-2817. 
12. Kumar, A., \& Kim, M. H. (2015). Convective heat transfer enhancement in solar air channels. Applied Thermal Engineering, 89, 239-261.

13. S. Y. Sawant, Sagar E. More \& H. M. Dange, "Design, Development and Performance Analysis of Anticorrosive Heat Exchanger “, IMPACT: International Journal of Research in Engineering \& Technology (IMPACT: IJRET), Vol. 2, Issue 5, pp. 285-292

14. Mokrani, O., Bourouga, B., Castelain, C., \&Peerhossaini, H. (2009). Fluid flow and convective heat transfer in flat microchannels. International Journal of Heat and Mass Transfer, 52(5-6), 1337-1352.

15. Peng, X. F., Wang, B. X., Peterson, G. P., \& Ma, H. B. (1995). Experimental investigation of heat transfer in flat plates with rectangular microchannels. International Journal of Heat and Mass Transfer, 38(1), 127-137.

16. Mahmoud, S., Al-Dadah, R., Aspinwall, D. K., Soo, S. L., \&Hemida, H. (2011). Effect of micro fin geometry on natural convection heat transfer of horizontal microstructures. Applied Thermal Engineering, 31(5), 627-633.

17. Murthy, P. V. S. N., Kumar, B. R., \& Singh, P. (1997). Natural convection heat transfer from a horizontal wavy surface in a porous enclosure. Numerical Heat Transfer, Part A Applications, 31(2), 207-221.

18. Starner, K. E., \& McManus Jr, H. N. (1963). An experimental investigation of free-convection heat transfer from rectangularfin arrays.

19. Yüncü, H., \& Anbar, G. (1998). An experimental investigation on performance of rectangular fins on a horizontal base in free convection heat transfer. Heat and Mass Transfer, 33(5-6), 507-514.

20. Güvenç, A., \&Yüncü, H. (2001). An experimental investigation on performance of fins on a horizontal base in free convection heat transfer. Heat and mass transfer, 37(4-5), 409-416.

21. V. Murali Krishna, "Heat Transfer Enhancement by using CuO-Water Nanofluid in aConcentric Tube Heat Exchanger-an Experimental Study “, International Journal of Mechanical Engineering (IJME), Vol. 6, Issue 1, pp. 11-20

22. Yildiz, Ş., \&Yüncü, H. (2004). An experimental investigation on performance of annular fins on a horizontal cylinder in free convection heat transfer. Heat and mass transfer, 40(3-4), 239-251.

23. Dogan, M., \&Sivrioglu, M. (2010). Experimental investigation of mixed convection heat transferfrom longitudinal fins in a horizontal rectangular channel. International Journal of Heat and Mass Transfer, 53(9-10),2149-2158.

24. Awasarmol, U. V., \&Pise, A. T. (2015). An experimental investigation of natural convection heat transfer enhancement from perforated rectangular fins array at different inclinations. Experimental Thermal and Fluid Science,68,145-154. 